\title{
Las producciones Calderón y la continuidad del cine industrial mexicano $(1960-1980)^{*}$
}

\author{
Silvana Flores ${ }^{* *}$ \\ Recibido: 2020-09-14 • Enviado a pares: 2020-09-20 \\ Aprobado por pares: 2020-11-21 • Aceptado: 2021-01-19 \\ https://doi.org/10.22395/angr.v19n39a3
}

\begin{abstract}
Resumen
Este trabajo analizará las problemáticas que el cine mexicano enfrentó tras el fin de su auge industrial en Hispanoamérica desde los años sesenta, partiendo de un estudio de caso: las estrategias de una familia de productores, los hermanos Calderón, destacados por elaborar películas de corte popular. Este artículo procura dilucidar las formas en que la cinematografía industrial en México buscó su continuidad en los mercados y la captación de públicos en tiempos de modernización y transformación de paradigmas sociales, y determinar las alternativas narrativas y estéticas promovidas por estos productores en sus films de los años sesenta a ochenta para lograr su permanencia en la industria en medio de la crisis. Para ello, se establecerá un panorama general sobre el estado del cine mexicano en aquel punto de inflexión, que contextualizará el estudio de caso, metodología a través de la cual se enumerarán las propuestas estéticas y narrativas planteadas por los Calderón, estableciendo una confluencia entre el contexto de crisis de la cinematografía mexicana, la tendencia de innovación estética y reflexividad de los llamados nuevos cines latinoamericanos que emergieron simultáneamente, y las propuestas de los Calderón en pos de la captación de públicos por medio de los géneros abordados durante estos años (el cine fantástico y de terror, el cine de luchadores y los films de ficheras). Los resultados obtenidos corroboran la existencia de una confrontación de tendencias en el cine mexicano del período que opone aquel cine industrialista con la alta cultura.
\end{abstract}

Palabras clave: industria cinematográfica; cine; géneros; crisis cultural; producción cinematográfica; espectador; narración; estilo artístico.

Este artículo fue escrito en el contexto de una investigación financiada desde el 2016 por el Consejo Nacional de Investigaciones Científicas y Técnicas (Conicet), en Argentina, bajo el nombre de Transnacionalidad en el cine industrial mexicano: las actividades cinematográficas de la familia Calderón y su influencia regional en Hispanoamérica. México

* Doctora en Historia y Teoría de las Artes por la Facultad de Filosofía y Letras de la Universidad de Buenos Aires. Investigadora Asistente del Conicet, con sede en el Instituto de Historia del Arte Argentino y Latinoamericano. Co-directora del Centro de Investigación y Nuevos Estudios sobre Cine (ClyNE), de la Universidad de Buenos Aires. Co-directora de la revista Imagofagia y miembro de la Asociación Argentina de Estudios de Cine y Audiovisual (Asaeca). Integra la cátedra de Semiología del UBAXXI. Email: silvana.n.flores@hotmail.com. Orcid: https://orcid.org/0000-0003-0991-029X. 


\title{
Calderón Productions and the Continuity of Mexican Industrial Cinema (1960-1980)
}

\begin{abstract}
This paper analyzes the problems that Mexican cinema faced after the end of its industrial boom in Latin America in the 1960s, based on a case study: the strategies of a family of producers, the Calderón brothers, known for making popular-style films. The article also seeks to elucidate the ways in which industrial filmmaking in Mexico sought the continuity in the markets and the attraction of audiences in times of modernization and transformation of social paradigms, and to determine the narrative and aesthetic alternatives promoted by these producers in their films from the sixties to the eighties in order to achieve their permanence in the industry in the midst of the crisis. To this end, a general overview of the state of Mexican cinema at that turning point will be laid out in order to contextualize the case study. Through this methodological approach the aesthetic and narrative proposals put forward by the Calderóns will be listed, establishing a confluence between the context of crisis in Mexican filmmaking, the trend of aesthetic innovation and reflexivity of the so-called new Latin American cinemas that emerged simultaneously, and the proposals of the Calderóns in pursuit of attracting audiences through the genres employed during these years (fantastic and horror films, wrestling films and ficheras films). The results obtained reaffirm the existence of a confrontation of tendencies in the Mexican cinema of the period that opposes industrialist cinema with high culture.
\end{abstract}

Keywords: film industry; cinema; genres; cultural crisis; film production; spectator; narrative; artistic style.

\section{As produções Calderón e a continuidade do cinema industrial mexicano (1960-1980)}

\begin{abstract}
Resumo
O presente trabalho analisará os problemas que o cinema mexicano enfrentou após o fim do seu ascensão industrial na Hispanoamérica dos anos sessenta, partindo de um estudo de caso: as estratégias de uma família de produtores, os irmãos Calderón, proeminentes por criar filmes de linha popular. Este artigo procura esclarecer as formas que a cinematografia industrial no México buscou sua continuação nos mercados e a captação de públicos em tempos de modernização e transformação de paradigmas sociais, e determinar as alternativas e estéticas promovidas por estes produtores nos seus filmes dos anos sessenta aos anos oitenta para conseguir sua permanência na indústria em meio a crise. Para isso, se estabelecerá um panorama geral sobre o estado do cinema mexicano naquele ponto de inflexão, que contextualizará o estudo de caso, metodologia através da qual se enumerará as propostas estéticas e narrativas planejadas pelos Calderón, estabelecendo uma confluência entre o contexto da crise da cinematografia mexicana, a tendência da inovação estética e refletividade dos chamados novos cinemas latino-americanos que apareceram simultaneamente, e as propostas dos Calderón em buscar públicos por meio dos gêneros abordados durante os anos (o cinema fantástico e de terror, o cinema de lutadores e os filmes de fichera). Os resultados obtidos confirmam a existência de uma confrontação de tendências no cinema mexicano no período que opõem ao cinema industrialista com a alta cultura.
\end{abstract}

Palavras chave: indústria cinematográfica, cinema, gêneros, crises cultura, produção cinematográfica, expectador, narração, estilo artístico. 


\section{Introducción}

En el transcurrir de las décadas del sesenta y setenta, el cine mexicano se vio envuelto en un período de crisis industrial, agotadas las fórmulas narrativas y los parámetros estéticos que habían podido mantenerlo entre los años treinta y cincuenta en el podio de las industrias cinematográficas de América Latina, con una visibilidad en los mercados y la posibilidad de expandirse hacia latitudes más lejanas, tal como lo certifican investigadores como Castro Ricalde y McKee Irwin (2011) o Peredo Castro (2011). La modernización de los cines a nivel mundial llevó a cambios forzados que respondían a los nuevos tiempos y paradigmas artísticos e ideológicos, produciéndose un agotamiento de los modelos imperantes y el planteo de producciones volcadas a nuevas experimentaciones estilísticas y temáticas orientadas a la concientización social. Desde la industria, con el declive de los estudios y de las figuras de renombre, aquello resultó un gran desafío de adaptación y mantenimiento de los públicos (Costa, 1988, p .57), en una región (Latinoamérica) que siempre ha tenido desventajas ante la hegemonía de cinematografías centrales como la de Hollywood.

A través de este trabajo, nos insertaremos en las problemáticas que los agentes del cine mexicano debieron enfrentar en este período, partiendo de un estudio de caso: la filmografía de una familia de productores mexicanos, los hermanos Calderón, destacados por su elaboración de películas de corte industrialista y popular. Esto con el fin de analizar las formas en que buscaron perpetuar sus carreras tras la modernización de los cines. Estos productores lograron un gran alcance en los públicos durante los años cuarenta y cincuenta alentando un abordaje transnacional del cine, el cual les permitió extender redes para su difusión en diferentes partes de Hispanoamérica, así como también implantaron una conexión con Estados Unidos desde las áreas de la exhibición y la distribución (Gunckel, 2015; Flores, 2020a). Aun a pesar de esa continua mirada foránea, la transnacionalidad de los Calderón no implicaba un desentendimiento de lo nacional, ya que, como afirma Lie (2016), ambos aspectos se constituyen mutualmente. Por otra parte, el entendimiento de la trayectoria de estos productores no se encuadra exclusivamente en lo industrial, pues, como establecen Shaw y De la Garza (2010), aquella perspectiva de abordaje del cine abarca además de este importante factor también los aspectos textuales, complementándose entre sí. Con el fin de especificar el recorte que signará a este trabajo, no se hará énfasis en los aspectos concernientes a las transacciones de producción, sino que se puntualizará sobre la segunda dirección, vinculada a las diferentes vertientes genéricas que acompañaron la planificación de sus films.

El artículo se estructura entonces en dos partes complementarias: el establecimiento de una contextualización de las circunstancias que llevaron a la crisis de la cinematografía mexicana, en la confrontación de la propuesta industrialista 
de los Calderón con la tendencia de innovación estética y reflexividad de los llamados nuevos cines latinoamericanos que emergieron simultáneamente, y en segundo lugar, tras dicho encuadre, el análisis propiamente dicho de las estrategias desplegadas por los Calderón en pos de la captación de públicos por medio de los géneros abordados durante estos años, a saber, el cine fantástico y de terror, el cine de luchadores y los films de ficheras y sexycomedias. Los Calderón estimularon dichos géneros debido a la pregnancia entre el gran público que empezó a manifestar en la cinematografía mexicana del período aquí a estudiar, y porque implicaron una renovación de antiguos paradigmas como el del cine de terror y los melodramas prostibularios que habían asentado al cine mexicano en el inicio de su industrialización. El propósito de estas indagaciones es examinar dichas variantes genéricas, elaborando así el nuevo perfil estético-narrativo del cine industrial mexicano tras el cese de su conocida Edad de Oro que duró hasta los años cincuenta, es decir, luego de su auge como potencia cinematográfica en la región.

Teniendo en cuenta lo dicho anteriormente, este trabajo parte de dos preguntas fundamentales. En primer lugar, ¿̇de qué modo los productores Calderón actuaron para buscar su continuidad en los mercados y en la captación de públicos en tiempos de modernización estética y de transformación de paradigmas sociales? En segunda instancia, y en conexión con ello, ¿cuáles fueron las alternativas narrativas y estéticas promovidas por estos en sus films de las últimas décadas de actividad que le habrían permitido alcanzar su permanencia en la industria del cine mexicano en medio de la crisis? En pos de estas problemáticas, se plantean los siguientes objetivos específicos: a) dar un breve panorama sobre las causas y consecuencias de la crisis industrial del cine mexicano tras los cambios a nivel mundial, b) distinguir y analizar el desempeño de las producciones de los Calderón en las décadas a trabajar, y c) discutir, con base a dichas distinciones, la funcionalidad de estos nuevos productos en el sostenimiento de la industria.

\section{Metodología}

La investigación, que es parte de un proyecto más amplio sobre el rol de los productores, distribuidores y exhibidores Calderón en la formación de vínculos transnacionales entre México e Hispanoamérica, buscará especificar un período acotado en la filmografía de estos agentes cinematográficos (que abarcó siete décadas en total) en donde consolidaron su postura como representantes de un cine marcadamente comercial y afianzado a las demandas del gran público. Por ello, este trabajo se desenvolverá en torno al análisis de un estudio de caso desde un enfoque historiográfico basado en investigación documental, que comprende la filmografía de estos productores en torno a las décadas del sesenta y ochenta, por lo cual se empleará el análisis textual de material filmográfico. Aquello será efectuado en dos etapas: en primer lugar, se 
establecerá un panorama general sobre el estado del cine mexicano en el período, que permitirá entender las circunstancias socioculturales que impulsaron la búsqueda de nuevos métodos de atracción de los públicos, y en segunda instancia se enumerarán las propuestas estéticas y narrativas planteadas por estos productores, en particular Guillermo Calderón, quien fuera el más activo entre sus hermanos por este tiempo.

El corpus de películas que comprende este período será examinado partiendo de las características genéricas de las cuales se derivan, con el fin de determinar las variaciones implantadas por ellos en el contexto de la instauración de films de difusión popular. La agrupación en categorías habilitará el ordenamiento del análisis: primeramente, se abordará una serie de títulos que forman parte de un ciclo de cine fantástico y de terror, anclado en cierta mixtura con mitos nacionales e internacionales. Se utilizarán como muestra dos películas de principios de los años sesenta dirigidas por Benito Alazraki: Muñecos infernales (1961)' y Espiritismo (1962). En segundo lugar, se analizarán algunos títulos provenientes de un género híbrido nacido en las arenas de la lucha libre mexicana, que imbricó elementos de aquel deporte con características de la primera categoría recién mencionada. En este punto del estudio se precisará subdividir al cine de luchadores en tres variantes: una vinculada a tramas desarrolladas en torno a la figura del luchador y sus acciones benéficas en pos de alguna causa (en particular, Santo, el Enmascarado de Plata), una segunda vertiente en la que el luchador cumple un rol secundario en la trama, haciéndose énfasis en el desenvolvimiento de una narración fantástica, que será explicitado a partir de la conocida serie de films sobre "la momia azteca" dirigida a fines de los años cincuenta por Rafael Portillo, y finalmente, la explotación del subgénero a partir de la inclusión de luchadoras femeninas, como modo de extender el alcance entre los públicos ante fórmulas narrativas desgastadas. El tercer grupo de films producidos por los Calderón que serán parte de este análisis está compuesto por un nuevo subgénero, las películas de ficheras de los años setenta a ochenta, variante erotizada de los melodramas de cabareteras de larga tradición en el cine mexicano.

\section{Resultados y discusión: hallazgos sobre la contextualización}

\section{Causas y efectos de la crisis industrial del cine mexicano}

Los años cincuenta trajeron consigo cambios significativos en la industria del cine mexicano. Para ese entonces, las fórmulas que habían logrado permanecer durante dos décadas (con el inicio del cine sonoro y la consecuente industrialización) empezaban a agotarse: los géneros perdieron potencialidad, las estrellas cinematográficas

Constituido como un film de culto, esta película no solamente fue distribuida en el interior de México, sino que también ha llegado a salas comerciales de la ciudad de New York (Estados Unidos) a través de la empresa Cinematográfica Mexicana Exportadora. Fuente: Archivo Permanencia Voluntaria. 
veían pasar los años, y el sistema de estudios, que había sido prolífico, ${ }^{2}$ entró en crisis, así como sucediera en todo el mundo, convirtiéndose esta época en un parteaguas que alentó nuevos abordajes del arte cinematográfico. A su vez, este momento trajo transformaciones que afectarían al cine desde su parte técnica y narrativa. Aquello derivó en el surgimiento de nuevos dispositivos (cámaras ligeras, utilización de sonido directo, el surgimiento de la fotografía a color, que fue tardía en América Latina), de narrativas modernizadas (con el empleo de tiempos muertos o la evidencia de la enunciación), así como también de tópicos de interés para los nuevos públicos, tanto en lo referente a las preocupaciones políticas como en el aligeramiento de la censura sobre tópicos sensibles como la sexualidad. Estos aspectos empezarían a emerger en los cincuenta, para consolidarse en las décadas subsiguientes, expandiéndose a cinematografías tanto centrales como periféricas. Tal como lo consideraba Paranaguá (2003), los cincuenta fueron un período peculiar que podríamos denominar como transitorio: "Illa tradición o el clasicismo parecen agotados, pero la modernidad aún está en gestación" (p. 159). Y este fenómeno, como dijimos, no sería solamente mexicano o latinoamericano, como lo demuestran la emergencia de corrientes modernizadoras del lenguaje cinematográfico en diferentes lugares del mundo, en particular la Nouvelle Vague, aunque también el cine directo estadounidense, el cinéma-vérité y la etapa tardía del neorrealismo italiano.

Además, debemos tener en cuenta la influencia que empezaría a ejercer la televisión, medio incipiente en México pero que igualmente afectaría los hábitos de percepción de productos audiovisuales, así como también sería una peligrosa competencia, alentando la configuración de nuevas propuestas cinematográficas que se ajustasen a las expectativas de un público en vías de transformación. Esto es de vital importancia, ya que tras el legado menguante de los grandes nombres del star-system mexicano, surgirían nuevas personalidades a tono con este medio emergente llamado televisión, entre ellos los luchadores (de los cuales hablaremos más adelante) y los personajes juveniles en su descubrimiento de nuevos ritmos musicales. Aunque pasaría largo tiempo hasta que un buen número de hogares mexicanos estuvieran equipados con un aparato de televisión, el cine encontraría aquí su primer gran competidor en el aspecto audiovisual, que derivaría a lo largo de las décadas en un cada vez mayor asentamiento del entretenimiento casero. ${ }^{3}$ A pesar de esta situación propulsada por el emergente medio, Ana Rosas Mantecón (2017) sugiere que la crisis de la exhibi-

2 México ha sido una de las principales industrias del cine latinoamericano en tiempos previos a la modernidad, poseyendo una infraestructura que le permitió posicionarse en la región. Respecto a los estudios, México contó con instalaciones de gran envergadura, entre las que se destacaron Clasa, Azteca, Churubusco y Tepeyac. Sin embargo, el alcance de la industria empezó a verse golpeado con el fin de la Segunda Guerra Mundial, cuando ya no era necesaria como aliada para la producción estadounidense, y, por lo tanto, recibiría menores recursos de aquel país.

3 Tengamos en cuenta que en este período la televisión era más bien una amenaza, pero que, en décadas posteriores, y más en la actualidad, con el asentamiento de lo digital que abarató costos de producción, empezaría a imbricarse con el cine para beneficio de las realizaciones. 
ción surgida a mitad de siglo no ha sido causada únicamente por la televisión, aquella constituía "el enemigo más obvio: era visual, ofrecía entretenimiento y se expandía mientras las salas desfallecían" (p. 191). Según Rosas (2000), también hubo cierto viraje a las clases medias, provocado por un aumento de los precios de las entradas, que ahuyentó a los espectadores de menores recursos, y, por otro lado, un desinterés por la diferente calidad de las películas que se harían en ese entonces. Este abandono de ciertos públicos es adjudicado a la proliferación de películas que se ajustan a la descripción de las producciones de los Calderón: "filmes nacionales comerciales de ficheras, rancheros, traileras, contrabandistas, narcotraficantes [...] se encaminaron a buscar al espectador de más bajo poder adquisitivo y de menores exigencias de México, Centroamérica y el Caribe" (Rosas, 2017, p. 194). Sin embargo, la televisión consolidó esta situación a partir de los sesenta cuando los sectores medios empezaron a adquirir con mayor asiduidad los aparatos. ${ }^{4} Y$ es de hecho en esa televisión donde los espectadores del cine de la Edad de Oro podían también acceder a sus films favoritos del pasado.

La tecnología que el cine de Hollywood fue constante en adquirir para instalar sistemas de proyección, propuestas fotográficas diferenciadas y sonidos envolventes que alentaran la afluencia de públicos en pos de una experiencia audiovisual a gran escala, no estaba tan disponible en cinematografías más periféricas, como es el caso de las latinoamericanas, y México no ha sido una excepción. Aun así, aparecerían algunas novedades como los intentos de hacer cine en 3D, que tuvo su ejemplo fallido en un film inacabado, Morning star, producido por Jorge García Besné, pariente político de los Calderón, el cual también lanzaría en dichas condiciones de fotografía la película de aventuras El corazón y la espada (Edward Dein y Carlos Véjar, Jr., 1953). ${ }^{5}$ Pero más allá de estos esfuerzos, la industria vio dificultadas sus estrategias de atracción, desembocando en un cierre de salas, entre otras consecuencias.

La televisión contraatacaba con productos seriados (algo que requería una permanencia de los espectadores), además de contar con la novedad de la transmisión en directo, experiencia que el cine no había logrado concretar a pesar de que tanto el cine como la televisión tienen en común la mediación de un dispositivo técnico. En México la invención tuvo su inicio entre finales de los años treinta y principios de los cuarenta, tras las experimentaciones del joven estudiante Guillermo González Camarena, generando la primera transmisión en 1946 y creándose el primer canal nacional tres años después. Aquello crecería a lo largo de la década del cincuenta, contándose

Rosas Mantecón (2000) indica que entre los sesenta y setenta hubo un descenso del 50 \% en la asistencia a las salas, tendencia que se mantuvo hasta mitad de la década del noventa. A la inversa, la adquisición de aparatos de televisión iría en aumento con el correr de los años.

5 Según Emilio García Riera (1993), la versión en tercera dimensión no tuvo estreno en Ciudad de México, a pesar de haber sido promocionada de esa manera (p. 102). 
con más empresarios que invirtieron en el nuevo sistema de entretenimiento, entre ellos Emilio Azcárraga Vidaurreta. La novedad que había sido para el antiguo público de cine las imágenes en movimiento y luego el sonido, fue reemplazada aquí por un factor diferenciado, basado en la inmediatez y en la posibilidad de hacer ingresar la pantalla al propio hogar, una pantalla de menores dimensiones, pero mayores posibilidades de cotidianidad. Así como había sucedido con la radio, que permitía escuchar en el espacio hogareño las voces de los artistas preferidos, ahora podrían tenerlos de cuerpo completo en la pequeña y monocroma pantalla de televisión.

Por otro lado, los años sesenta en México vendrían a constituirse en el eco de los nuevos cines que estaban emergiendo en la región, los cuales dieron comienzo a la trayectoria de otros directores, algunos ya en actividad en los cincuenta, como Benito Alazraki, con su film Raíces (1953) o Carlos Velo, con Torero (1956), y luego Felipe Cazals, Alberto Isaac, Arturo Ripstein, Jaime Humberto Hermosillo y Jorge Fons, más volcados a las preocupaciones sociales, y respaldados por una intelectualidad reunida en revistas como "Nuevo Cine" y por la creación de cineclubs. ${ }^{6}$ Ello traería también nombres de pensadores y críticos de cine mexicano como Emilio García Riera, José de la Colina, Salvador Elizondo, Carlos Monsiváis, Paul Leduc, Gabriel Ramírez, Jomi García Ascot y Jorge Ayala Blanco, generando un ambiente de mayores expectativas creativas, que tuvo entre sus resultados la fundación en 1963 del Centro Universitario de Estudios Cinematográficos (CUEC). Este funcionó como escuela de cine insertada en la Universidad Nacional Autónoma de México (UNAM), dando como resultado una nueva generación de realizadores. Del lado más afianzado a la vieja industria, estas paulatinas transformaciones fueron un desafío notable para los productores, que debieron encontrar nuevos modos de captar los públicos ante el declive de lo que había caracterizado a los cines clásicos: la filmación en estudios, la explotación de fórmulas genéricas de éxito (la comedia ranchera, los melodramas cabareteros, el cine indigenista) y el sistema de estrellas.

Los setenta encontraron al cine mexicano altamente estatizado, lo cual se reflejó en la instalación de productoras como Conacine, Conacite I y Conacite II (Saavedra Luna, 2006, p. 109), como muestra del esfuerzo de crear una infraestructura integral que incluyó "producción, servicios a la producción, distribución y exhibición, e incluso capacitación, promoción y publicidad" (Imcine, citado en Martínez Piva, Padilla Pérez, Schatán Pérez y Vega Montoya, 2010, p. 29). El interés era "levantar una industria en crisis, para reemplazar a los viejos productores y dar un nuevo aire a la cinematografía en su conjunto" (Frías, 2013, p. 99), provocando que los realizadores independientes tengan un mayor apoyo del Estado. Eso generaría una disputa entre el presidente

6 Es notable también la presencia del español Luis Buñuel, que trabajó en México entre 1946 y 1964, constituyendo una filmografía de tintes más autorales que trajo nuevos aires a la cinematografía, aun inmersa en los patrones del clasicismo. 
Luis Echeverría y los productores Gregorio Walerstein, Raúl de Anda y Guillermo Calderón, que representaban la vieja guardia del cine mexicano, con los reparos de que estos hacían un cine de baja calidad estético-narrativa, por fuera de las expectativas culturales que se querían impartir al nuevo cine. ${ }^{7}$ En un discurso pronunciado en 1972, el presidente lanzó su embestida proponiendo que el cine, a pesar de ser "un artículo de consumo popular", no debe perder de vista su obligación de "cumplir con una ingente tarea de pedagogía social" (en Asociación de Documentalistas de México, 2007, p. 24). En contraposición, los productores privados apostarán a su supervivencia con el lanzamiento de nuevas fórmulas de interés para el público general, aprovechando las posibilidades de una censura más alicaída que permitía introducir desnudos o semidesnudos, así como la aparición de nuevos personajes de ficción o de figuras estelares emergentes. En estos años setenta, aparecerían también algunas instituciones que alentaron otro tipo de producciones, de corte más autoral, como el Banco Nacional Cinematográfico, fundado en 1971 y dirigido por Rodolfo Echeverría, hermano del presidente, el cual será responsable del aliento a ese otro tipo de producción, contrapuesta a la de los productores privados. ${ }^{8}$

Estas diferenciaciones marcaron una controversia entre la cinematografía como fuente de conciencia social, por un lado, y como entretenimiento, por el otro. Pero debemos entender, como determina Costa (1988, p. 139), que la naturaleza del público nunca es homogénea, ya que las preferencias por ciertos abordajes del cine dependerán de factores socioculturales y geográfico-económicos. Guillermo Calderón, en su rol de presidente de la Cámara Nacional de la Industria Cinematográfica, afirmaría que no era la función de los productores educar a las personas,? y llegaría a establecer su queja sobre las pretensiones de invertir capital en títulos para la cultivación de los públicos (Costa, 1988, p. 171). En la misma línea se expresaría el cineasta René Cardona, quien dirigiera algunas de las películas producidas por los Calderón en el período aquí consignado:

El cine es un entretenimiento, y quien me diga que su función es educar, yo le respondo: ¿qué hacen entonces las universidades, están cerradas? Porque si bien las universidades están para instruir, el cine está para informar entreteniendo [...] Para que la gente vaya a descansar de sus propios problemas y entonces, con

7 Algunas de las películas de este período que fueron apoyadas por el Estado fueron Canoa (Felipe Cazals, 1975), La pasión según Berenice (Jaime Humberto Hermosillo, 1976), Actas de Marusia (Miguel Littín, 1976) y Cascabel (Raúl Araiza, 1977). Aunque autores como Paola Costa (1988, p. 161) consideran que el sustento estatal a estos films es una muestra del interés de ayudar a la industria en crisis, y lo hicieron precisamente con títulos que evidencian una sintonía con las innovaciones culturales que el Nuevo Cine Latinoamericano había instalado desde hacía una década, mostrando las pretensiones didácticas y de alta cultura de las que hacía alarde el gobierno.

8 El Banco se cerrará en 1977, bajo el gobierno de José López Portillo, quien establecerá políticas cinematográficas favorables a los productores privados.

9 Una declaración similar haría el anciano Guillermo Calderón en una entrevista registrada en el film Perdida (Viviana García Besné, 2009), en donde se registra su trayectoria y la de su familia. 
temática muy hábilmente utilizada para mandar mensajes, mensajes positivos, educativos, para dirigir estos mensajes es el cine. (Meyer, 1976, p. 69)

El director cierra su idea estableciendo su inconformidad con la politización del cine, argumentando la necesidad de que aquel arte llegue a cualquier tipo de público y no solamente a un sector afín a las propuestas del cineasta, poniendo en duda finalmente que aquella tendencia pudiera tener continuidad sin el patrocinio del Estado. La vieja batalla entre el cine de autor y los llamados "churros"10 son un signo de la crisis que este período estaba atravesando en materia de la posibilidad de aunar creación cinematográfica y accesibilidad a los públicos. Las declaraciones de Cardona se suman al pensamiento de los productores privados, quienes justificarían la introducción de tramas superficiales sin pretensiones de alta cultura bajo la base de que esas películas, de gran receptividad en comparación con el llamado cine de autor, permitían el sostenimiento "del aparato industrial, lo que implicaba a un numeroso grupo de trabajadores, proyeccionistas, taquilleros, etc., y sus familias, para quienes ésa era su fuente trabajo [sic] y de bienestar social" (Saavedra Luna, 2006, pp. 109-110).

En resumen, entre los años cincuenta y setenta el cine mexicano se mantuvo en una lucha por su subsistencia, agotados los recursos de éxito que le habían puesto a la cabeza de las cinematografías latinoamericanas a lo largo de las décadas anteriores, manteniendo una confrontación entre dos maneras de hacer cine: aquella que alentara la intervención política, tal como se proponía en otros países de la región como Cuba, Argentina, Brasil, Chile, Bolivia o Colombia, y la que estaba más a la orden de la complacencia de los públicos que buscaban en el cine un entretenimiento, enfoque que asumirá con ímpetu el productor Guillermo Calderón, como representante de esta segunda línea que aquí abordamos.

\section{Resultados y discusión: hallazgos sobre las muestras}

\section{Nuevos tiempos, nuevos géneros, nuevos productos audiovisuales}

Los años sesenta trajeron un entorno desafiante pero promotor de nuevas posibilidades estético-narrativas, a pesar de la crisis industrial en gestación y de los elementos de competencia que llevaron a una disminución de la asistencia a las salas. Para poder sostener las taquillas, los productores se vieron envueltos en la encrucijada de hacer frente a las nuevas demandas, en un contexto en donde la puja por el cine popularcomercial que buscaron continuar iba en desmedro del incentivo del Estado por traer a la luz films con preocupaciones sociales. Siguiendo la línea eminentemente industrialista que es objeto de nuestro estudio, entendemos que los Calderón optaron por una visión más ligada al entretenimiento, aunque ya no podían seguir propulsando

10 El término "churros" se usa popularmente en el entorno del cine mexicano para dar cuenta de las producciones abaratadas en presupuesto, pero también en calidad narrativo-estética. Según Coria (2018), aquella palabra fue acuñada por primera vez por el productor Mauricio de la Serna, en la década del cuarenta, para describir a la producción nacional. 
los géneros y las estrellas que antes les habían dado notoriedad, como lo fueron mayormente las películas de rumberas, de gran éxito hasta mediados de los cincuenta.

Por tal motivo, aparecieron en el listado filmográfico de dichos productores diferentes categorías genéricas, entre las que destacaremos tres: primeramente, un ciclo de cine fantástico y de terror, orientado a la mixtura entre mitos universales y nacionales; en segunda instancia, la proliferación del cine de luchadores, con los personajes del Santo y Blue Demon como sus principales representantes, ${ }^{11}$ y finalmente, entrados los años setenta, el cine de ficheras, el cual reincorpora al espacio del cabaret que ya había sido central en los films de rumberas, ${ }^{12}$ al que se suma una vertiente por fuera de dicho espacio, que consistió en las sexycomedias (películas de enredo erotizadas como las anteriores, pero por fuera del espacio del cabaret), tomando la oportunidad que creaba cierta liberación de los organismos censores propia de la época del destape.

En lo referente al cine fantástico, de terror y de luchadores, su emergencia se dio simultáneamente, y eso explica la razón de su notable hibridismo. El cine mexicano en su generalidad introdujo una innumerable cantidad de films protagonizados por monstruos como momias, hombres lobo, vampiros, zombies y algunos otros seres fantasmales, así como también por científicos locos que hacen sus experimentos con base a ambiciones de progreso. Los luchadores fueron sus instrumentos para el mal, pero también se levantaron como héroes para salvar al mundo de las desviaciones "mesiánicas" de estos villanos.

En principio, hablaremos del cine de terror y fantasía que produjeron los Calderón como una díada genérica, planteada siempre bajo los parámetros del hibridismo que notaremos a lo largo de los análisis. Vale aclarar inicialmente las distinciones entre estos géneros. En cuanto al terror, su denominación se basa en la reacción emocional que este genera en el lector (Carroll, 2005, p. 62), o espectador en nuestro caso, y tiene una particularidad esencial, asentada en la ruptura de una normalidad, vinculada según Wood (1985, p. 204), a los comportamientos sociales dominantes, pero por medio de una figura aterrorizante, resumida en el término "monstruo" (adaptable a todo tipo de entes, tanto humanos como inhumanos). Conforme a sus diferentes manifestaciones, el cine de terror puede adquirir una iconografía asociada a espacios asolados y lúgubres, que amenazan desde su visualidad la integridad física de los personajes, amenaza proyectada en los espectadores a través de un efecto de identificación.

\footnotetext{
"Según registros de Paola Costa (1988, p. 58), para 1961 la comedia ranchera, género de largo alcance en México, pasó a tener solamente seis títulos; las películas de cómicos fueron once, cuando el año anterior habían sido el doble, los westerns bajaron de veintidós a once títulos y los melodramas, género por excelencia a lo largo de las décadas, llegaron a un somero número de catorce películas. En dicho contexto, las películas de luchadores fueron la gran novedad.

12 Vale aclarar que los Calderón no fueron los únicos productores que lanzaron películas de rumberas, aunque sí desarrollaron una prolífica filmografía al respecto.
} 
En lo referente al fantástico, son aplicables las determinaciones dadas por Todorov (1981) respecto a la literatura: parte de la aparición en nuestra cotidianeidad de "un acontecimiento imposible de explicar por las leyes de ese mismo mundo familiar" (p. 18). En consecuencia, destaca que los personajes envueltos en aquella trama fantástica tratan de buscar explicaciones, que rondan entre la comprensión de que se está delante de una ilusión o una imaginación, y la aceptación de que aquel evento extraño forma parte de la realidad, aunque con características incomparables con las de nuestra realidad tangible. Sin embargo, autores como Roas (2018) remarcarían posteriormente que la noción de lo fantástico siempre estará directamente relacionada con la concepción de la realidad que posean los sujetos que se enfrentan a ese otro mundo (pp. 5-8). La realidad decimonónica no puede ser comparable a la presentada en tiempos contemporáneos, con modificaciones en las cosmovisiones, y aún más, con los avances tecnológicos que también cambian el panorama, como establece el autor hablando de la era postmoderna.

Finalmente, es menester mencionar un género aledaño, que no aparece en su mayor expresividad en estos films más que con algunos rasgos aislados: la cienciaficción puede tomar algunas nociones propias de aquella extrañeza propuesta por lo fantástico, pero sin apuntar a la sobrenaturalidad, sino más bien a lo fáctico. De acuerdo con las reflexiones de Novell Monroy (2008) sobre las concepciones teóricas que ha suscitado este género, tanto la literatura como el cine de ciencia-ficción priorizan la exploración de ideas más que el desarrollo de la narrativa, que tiene en el cine un efecto particular de espectacularidad (p. 85). Esto provocaría que el cine de ciencia-ficción explote el espectáculo en sí mismo a través de lo que podríamos llamar su audio visualidad. Aquello puede explicar la proliferación de films de ciencia-ficción en el cine mexicano posterior a su época dorada, comenzando desde la década del treinta, siendo el país latinoamericano que mayor cantidad de películas de este género produjo y promoviendo así la revalidación de la industria (García, 2017, p. 629). En todos estos géneros podemos encontrar un eje común, reflejado en una mirada maniqueísta, valores representados en las caracterizaciones y funciones de cada personaje de la trama, pero también el factor de lo sobrenatural como elemento que contraría a los personajes (desde el miedo, en el caso del terror, o en la extrañeza e incertidumbre, en el fantástico).

Estos elementos aparecerán combinados en las producciones de los Calderón, consolidándose como un modo de palear la crisis industrial con nuevos tópicos y personajes. La aparición de una oleada de películas fantásticas y de terror no era una novedad en los años sesenta, pues ya había antecedentes de este tipo de obras cinematográficas en México, como es el caso de La posada sangrienta (Fernando A. Rivero, 1943), abordada en un tono de comedia, en contraposición con las más solemnes de su clase La llorona (Ramón Peón, 1933) y El fantasma del convento (Fernando de Fuentes, 
1934), dos de los títulos más llamativos que le precedieron, que no fueron producidos por los Calderón, pero que estos conocían por participar en la distribución de los mismos a través de su empresa Azteca Films (Catálogo Azteca Films, Inc., s.f.). ${ }^{13}$ Emprender nuevamente producciones de esta vertiente genérica que había alcanzado productividad cuando la industria cinematográfica mexicana comenzó, podría ser un buen impulso para el renacer que el cine de este país requería tras el fin de su Edad de Oro. Como adelantamos, aquí nos centraremos en dos films dirigidos por Benito Alazraki, Muñecos infernales (1961) y Espiritismo (1962), que resumen algunos de los elementos propios de esta mixtura genérica característica del cine del período, a la que los Calderón se sumaron con vehemencia.

En la primera película, siguieron una fórmula similar a la que habían implementado en una serie de films recientes, la trilogía de la Momia azteca, conformada por La momia azteca (1957), La maldición de la momia azteca (1957) y La momia azteca contra el robot humano (1958), todas bajo la dirección de Rafael Portillo. Esos ingredientes fueron: a) la contraposición entre el bien y el mal como dos terrenos irreconciliables e identificables con determinados personajes, despojándoles de ambigüedad, b) la mención de creencias asociables a la superstición o a una religiosidad ancestral, marcadamente opuesta con el cristianismo, como es en este caso la práctica del vudú y sus fetiches, c) la presencia de científicos, representantes de una visión racionalista y práctica, que se encuentran en perplejidad y descreimiento ante los hechos sobrenaturales acaecidos, y d) la aceptación de aquellas situaciones por parte de estos personajes como algo que está aconteciendo en la realidad y sobre lo cual combatirán con las herramientas ofrecidas por su cultura. Muñecos infernales (1961) mantendrá también al actor protagonista de aquella serie, Ramón Gay, en una clara asimilación para los espectadores afines, pues en todos estos films interpretó a un científico. Su pareja, por su parte, es una antropóloga especialista en ritos indígenas, y junto a ella presenciará una serie de muertes inexplicables, producto de una maldición vudú tras el sacrilegio perpetrado por una expedición en Haití. Todas estas películas dedican sus primeras escenas a establecer una explicación por boca de algún letrado que sitúa en conocimiento al espectador. En este caso, la antropóloga se encarga de relatar las prácticas religiosas haitianas, al mismo tiempo que advierte al resto de los científicos acerca del error de mantenerse escépticos ante las consecuencias de sus intromisiones, asimilándose así aquellos dos polos no tan irreconciliables que representan la realidad conocida y los elementos fantasiosos propuestos por Todorov (1981) y Roas (2018).

13 Aclaramos que el padre y tío de los Calderón, los hermanos José y Rafael Calderón, abrieron una distribuidora de films en 1932, la Azteca Films Distribuiting Co., que tuvo accionar principalmente en Estados Unidos, difundiendo cine mexicano entre los públicos hispanos, además de regentear salas cinematográficas a ambos lados de la frontera México-Estados Unidos; por tal motivo, gran parte de los títulos que fueron surgiendo durante el tiempo de su funcionamiento pasaron por manos de estos empresarios. Para mayores detalles sobre la actividad de la familia Calderón en la distribución y exhibición ver Flores (2018a, 2020a). 
Desde la perspectiva audiovisual, la película utiliza los recursos tradicionales del género, buscando asegurarse el efecto de sorpresa, intriga y terror, tales como truenos, oscuridad (combatida por medio de candelabros o lámparas con haces de luz tenues, generando claroscuros), así como sonidos chirriantes y aullidos, insertos en espacios ordinarios como hospitales, los hogares o estudios de los científicos. La recurrente aparición de muñecos vivientes con el rostro de los personajes asesinados en el transcurso de la maldición, y el empleo de una música que alienta el ambiente inquietante, incentivan el efecto de terror procurado, al que se añade el sonido de instrumentos de viento en cada ocasión en que las víctimas son ejecutadas, aludiendo con ello a un imaginario sobre las raíces rituales que originan esas muertes.

En Espiritismo (1962), la trama aborda un ambiente signado por problemas vinculados a la cotidianeidad: la desesperación de un matrimonio ante las dificultades económicas, que los lleva a involucrarse en prácticas espiritistas. En este caso, esa realidad otra que aparece en el cine fantástico y de terror se inmiscuye en el entorno natural por curiosidad y voluntad de los personajes. Como en el film anterior, aquí también se parte de una iconografía asociada al suspenso y el terror, con la proyección de sombras, claroscuros y el uso de planos detalle que fragmentan esa realidad. Desde el plano sonoro, una música ambiental de tono melancólico y con redoblantes colabora en la configuración de esa simbiosis de realidades, sumado al empleo de truenos como efectos de sonido que acompañan las sesiones espiritistas.

Esta película también inserta la dicotomía entre lo racional y lo sobrenatural, y confronta dos tipos de espiritualidades: aquella asociada con la práctica que da título al film y la de la cristiandad sobre la cual está asentada la cultura a la cual pertenecen los protagonistas. Para tal fin, también se identifican personajes signados por la incredulidad ante el espiritismo, especialmente los hombres, asociada a una sensación de inquietud ante lo desconocido, así como también otros que buscan validar dicha práctica. En medio de ellos, el matrimonio protagonista es introducido en la encrucijada de tomar posición ante esa otra realidad, optando por acceder a ella, elección que se encargarán de definir como peligrosa desde el mismo comienzo del film a través de un flashback que sitúa la trama. Así, aunque la película busca generar un efecto de fascinación por lo extraño y se interesa en alentar la sensación emocional gestada por el cine de terror, se encargará desde el plano de la enunciación de sentar posición contra lo que muestra. Lo sobrenatural es aquí un elemento de consecución de soluciones ante los conflictos dramáticos, pero que será continuamente reprendido, y como consecuencia, castigado en el discurrir de los eventos relatados.

Por otro lado, dentro de esta línea del cine fantástico y de terror se encuentra una variante que el cine mexicano explotaría en diferentes niveles de intensidad entre los años cincuenta y setenta: la inclusión de los célebres deportistas de la lucha libre, que 
estaban teniendo suceso también en la televisión y en los medios gráficos ${ }^{14}$. Destacan entre ellos Santo, el Enmascarado de Plata, y Blue Demon, que fueron los luchadores que más veces aparecieron en las producciones Calderón. El primero ofició de héroe y el segundo solía forjar su personaje en el rol del villano (o del rudo, según la jerga de la lucha libre), aunque los Calderón unieron a ambos en amistad, en pos de una misión benéfica asignada a ellos en las tramas. Otro personaje que ha tenido pregnancia en los films de estos productores ha sido el Ángel, que formó parte de la serie de la Momia azteca; y en el muestrario de la lucha libre que se efectúa en estas películas se encuentran también mujeres luchadoras, en especial la dupla de Loreta y Rubi.

Respecto al Santo, su intervención en el cine tuvo inicio con dos películas filmadas en Cuba: Santo contra el Cerebro del mal y Santo contra Hombres Infernales, ambas dirigidas por Joselito Rodríguez en 1958. A partir de allí, el conocido luchador, llamado en realidad Rodolfo Guzmán Huerta, participaría en alrededor de media centena de películas, un buen número de ellas producidas por la familia Calderón, bajo esta mixtura genérica arriba mencionada. Con el correr del tiempo, y ante la obtención de una fórmula de éxito, las películas fueron consolidando ciertos estereotipos y una estructura narrativa homogénea entre un título y otro, que responde a características que detallaremos a continuación.

En primer lugar, los films parten de una contraposición entre los valores antitéticos del bien y el mal, en los que el Santo forma parte del primer concepto del binomio. Del lado del mal se suman una serie de personajes, que se sintetizan en la figura de lo monstruoso, ya sea por su sobrenaturalidad (al provenir de un espacio de ultratumba, de otro planeta o de alguna leyenda nacional o internacional, como la Llorona o Frankenstein) o por sus intenciones malévolas. En este último caso, suele aparecer una figura asociada a la experimentación científica, bajo intenciones de autoglorificación propias de alguna clase de delirio místico. Estos científicos, que poseen casi siempre una apariencia de normalidad, tienen también súbditos tanto humanos como sobrenaturales, que entrarían bajo esa denominación de lo monstruoso: por el énfasis puesto en algún defecto físico (una joroba, una dificultad para el habla, una deformación en el rostro) o por provenir de una realidad otra. Como establece Fernández Reyes (2007, pp. 119-122), el mal está en muchos casos asociado al condicionante de la apariencia física o lo biosociológico, lo cual lleva a dichos personajes a unirse inevitablemente a un entorno criminal. Por otra parte, así como el Santo utiliza sus habilidades para la lucha libre en pos de sus misiones salvíficas, también el villano suele enviar a su encuentro otros luchadores, asociados al mal. El maniqueísmo que aquí damos a

14 Según Fernández Reyes (2007, p. 106), se considera el inicio de los films de luchadores a El enmascarado de plata (1952), dirigida por René Cardona, que no debe confundirse con el apodo del Santo, pues este debutaría en el cine algunos años después. Sin embargo, aquel mismo año surgieron otros tres títulos del subgénero: La bestia magnífica (1952), de Chano Urueta, El luchador fenómeno (1952), de Fernando Cortés, y Huracán Ramírez (1952), de Joselito Rodríguez. Para más detalles sobre estas películas, ver Aviña (2004). 
conocer se ve reflejado aún en los títulos, que suelen ser un símil de los anuncios de lucha libre en las famosas arenas: Santo contra los jinetes del terror (1970), dirigida por René Cardona, Santo contra la mafia del vicio (1971), dirigida por Federico Curiel, Santo contra la hija de Frankestein (1971), dirigida por Fernando Osés y Santo y Blue Demon vs. Drácula y el Hombre Lobo (1973), dirigida por Miguel M. Delgado, son solo algunos de ellos.

En segundo lugar, las películas suelen tener momentos dedicados a la exhibición de un espectáculo de lucha libre. En ocasiones esto se realiza en la primera secuencia, aun antes de que se introduzca la trama, retomándose el espectáculo tanto a la mitad como al final del film. Por fuera de estos momentos la lucha libre es realizada en calles, parques, cementerios, ruinas arqueológicas o residencias, como un modo de insertar escenas de acción que capturen la atención del público. En Santo en la venganza de la momia (1971) el luchador es presentado en acción en el ring tras los títulos de crédito, en un muestrario de las habilidades técnicas del Santo, de su carácter invencible y de su popularidad. La capacidad de convocatoria de estas presentaciones en la televisión es desplazada hacia el cine antes de introducir la trama narrativa, algo que se hará inmediatamente después del espectáculo con la presentación de la misión a la que se deberá enfrentar, que incluirá, como el título lo indica, los seres sobrenaturales propios del cine fantástico.

A modo de cierre, la película volverá a mostrar al Santo en el ring, pero esta vez teniendo el espectador incorporadas las características desplegadas en el desarrollo de su personaje: su destreza frente a contrincantes más poderosos y los afectos adquiridos tras su aventura en la selva donde transcurre la acción. En Santo y Blue Demon vs. Drácula y el Hombre Lobo (1973) este rasgo se ve potenciado por la inclusión de peleas en el ring a mitad de la trama, donde los luchadores combatirán con emisarios sobrenaturales del mal. Por último, y al igual que sucediera con los films fantásticos y de terror sin luchadores, el enfrentamiento con aquellas variadas fuerzas malévolas no se da sin antes presentar una postura de escepticismo y racionalidad, aun en los mismos luchadores, que finalmente deben aceptar esa otra realidad como algo que forma parte de lo cotidiano, pues se presenta para pelear contra ellos. Así sucede con los fallidos intentos de convencer a un científico acerca del estatus de leyenda de La Llorona que hace el luchador en Santo y Mantequilla Nápoles en la venganza de La Llorona (1974), dirigida por Miguel M. Delgado. Estas circunstancias, que se van repitiendo en los sucesivos films, permiten introducir los rasgos de esa otra realidad presentada por el cine fantástico para confrontarla con una cotidianeidad en la que los luchadores aportarán características sobresalientes, que también los distinguen de aquella realidad común que buscarán restablecer a su punto de normalidad ${ }^{15}$.

15 En Santo contra la hija de Frankestein (1971) se adjudica cierta sobrenaturalidad también al propio luchador, al afirmarse que su sangre tiene un factor denominado "TR", que lo hace diferente a otros seres humanos. 
Estos ingredientes hacen también su aparición en la serie de la Momia azteca antes nombrada. ${ }^{16}$ En todas sus ediciones, los títulos de crédito introducen a un grupo de luchadores, entre ellos el Murciélago Velázquez, que ya había participado en otra célebre película de este tipo en México, la reciente Ladrón de cadáveres (1957) de Fernando Méndez. Sin embargo, aunque este luchador y sus compañeros son mencionados bajo esa denominación, en el desarrollo de la trama son caracterizados como simples matones, a las órdenes del villano de turno, el Dr. Krupp, un científico desquiciado que se hace llamar coincidentemente el Murciélago. La maldición de la Momia azteca (1957) incluye también al personaje del Ángel, interpretado por el actor y luchador Crox Alvarado, el cual viene a instalar en esta serie el paradigma de la doble personalidad de los héroes y villanos, y sí aparece bajo el ropaje propio de los luchadores. La máscara característica de estos alentaría aquel desdoblamiento, aprovechado para la generación del misterio. En el caso del Ángel, se produce un contraste con el personaje del Pinacate (un aliado cobarde de los protagonistas del film), que resultan ser la misma persona; mientras que el Murciélago, tras el cual se esconde el doctor, busca el tesoro azteca cuyo mapa está encriptado en dos reliquias profanadas que estaban bajo el resguardo de una momia. Si bien estas películas insertan al Ángel para sumarse a la lista de films de luchadores, no existe en ellas una demostración espectacular de la lucha libre propiamente dicha. Fuera de aquellas diferencias, la serie evidencia la misma disposición al maniqueísmo y al enfrentamiento de fuerzas espirituales de los demás títulos fantásticos y de terror analizados, pues la maldición generada por la profanación de los objetos es contrapuesta con las tradiciones culturales occidentales, y tienen a Ángel como representante del bien. Este tipo de producciones fueron de éxito probado no solamente en México, sino que permitieron mantener al cine nacional en boca de otros países, como lo demuestra la epístola enviada por Guillermo Calderón a Guillermo Carter, representante de la distribuidora internacional Películas Mexicanas en Chile, el 7 de septiembre de 1961:

Yo produje unas películas que se llaman La Momia Azteca, La Maldición de la Momia y La Momia Azteca vs El Robot. Estas películas, aunque te parezca extraño, fueron adquiridas en Italia, España, y acaba de entrar la primera de ellas en Brasil con estupendos resultados. No crees tú que valdría la pena que vieras una copia de La Momia Azteca, o cuando menos solicitaras una sinopsis de la misma, ya que como antes te digo han sido películas de un gran éxito en taquilla. (Calderón, 1961) ${ }^{17}$

\footnotetext{
16 Es importante aclarar que la última película de la serie tuvo una versión doblada al inglés: The robot vs. the aztec mummy (1964), realizada por iniciativa del productor estadounidense K. Gordon Murray, el cual la distribuyó por su país en desconocimiento de su productor mexicano, Guillermo Calderón, con lo cual la pregnancia de estos films no se circunscribió a la nueva industria del cine mexicano, sino que traspasó fronteras, transformando estas películas en films de culto. Lo mismo sucedería con algunos de los títulos protagonizados por el Santo. Para mayores detalles sobre las implicancias transnacionales de estas versiones dobles, ver Syder y Tierney (2005) y Flores (2018b).

17 Según documentos de taquilla ofrecidos por la Cinematográfica Mexicana Exportadora, La momia azteca se ha estrenado en salas comerciales de Colombia, Venezuela, Guatemala, Costa Rica, Cuba y Estados Unidos, mientras La maldición de la momia azteca (1957) hizo lo propio en Colombia, Venezuela, Perú, Honduras y Estados Unidos. El último título de la trilogía fue distribuido tanto en Colombia como en Perú. Fuente: Archivo Permanencia Voluntaria.
} 
Por último, es menester mencionar también las películas de luchadoras. Estas surgieron en los años sesenta y consisten en títulos como Las luchadoras contra el médico asesino (1963), Las luchadoras contra la momia (1964), ${ }_{18}^{8}$ Las lobas del ring (1965) y Las luchadoras vs. "Robot asesino" (1969), todas dirigidas por René Cardona. Como se aprecia con estas nominaciones, aquí se retoma a la lucha libre como eje del relato, partiendo de las figuras femeninas como un modo de establecer una variante que interese a los públicos ante la repetición de fórmulas. Estos films también están poblados de científicos delirantes con ansias de magnificación, policías incrédulos ante las amenazas de seres fuera de la normalidad y una proliferación de escenas de peleas, tanto en el ring, donde el espectáculo define también el conflicto dramático, como en espacios más cotidianos, en donde irrumpen seres como momias, robots, zombies, e incluso orientales (en una suerte de estigmatización de lo foráneo). Las tramas envuelven situaciones misteriosas que afectan la vida de sus protagonistas, dos luchadoras interpretadas por Lorena Velázquez (Loreta) y la originaria de Estados Unidos Elizabeth Campbell (Rubi). ${ }^{19}$ Estas utilizan sus habilidades deportivas para dirimir los obstáculos asistiendo a las fuerzas policiales (y aun sobrepasando las capacidades de dicha institución), y se enfrentarán a todo tipo de criaturas, así como a numerosos rufianes y a otras luchadoras humanas, muchas de ellas signadas por un debilitamiento de su voluntad por parte del villano, y que generalmente son puestas en contraste con las protagonistas con base en una actitud más masculinizada. Estas producciones también contaron con popularidad en las salas nacionales y extranjeras, como parece promocionar Guillermo Calderón a su distribuidor en Brasil, Antonio Expédito Fernández, representante de Películas Mexicanas de aquel país, en carta fechada el 4 de marzo de 1965:

No siempre tiene un Productor la suerte de lograr una película tan taquillera como Las Luchadoras contra la Momia, por lo que consideré oportuno poner a usted en antecedente, ya que no sólo [sic] en Colombia ha resultado un acierto, sino en todas las plazas donde se ha exhibido. (Calderón, 1965)

Por último, el cine de ficheras surgió en un momento de la cinematografía, el año 1975, en donde esta ya se había estatizado, y a pesar de no constituir películas de interés cultural, fue tan grande su popularidad que permitió sostener financieramente a la alicaída industria. La película iniciadora fue Bellas de noche (las ficheras) (1975) del director Miguel M. Delgado, bajo la égida de Guillermo Calderón, y con inspiración en una obra teatral coetánea dirigida por quien sería uno de los principales realizadores de este subgénero: Víctor Manuel Castro. Aunque es necesario reconocer el antecedente de un film reciente, Tívoli (1974) de Alfonso Arau, que tuvo como protagonista al espacio del cabaret que tanto había sido representado en el cine de los cuarenta y cincuenta. A partir del éxito de Bellas de noche (1975), Calderón lanzaría un gran núme-

\footnotetext{
18 Al igual que lo que sucediera con la serie de la momia azteca y con los films del Santo, esta película tuvo una versión doblada al inglés, titulada The wrestling women vs. the aztec mummy (1964)

19 En Las luchadoras vs. "Robot asesino" (1963) la dupla de Loreta y Rubi es reemplazada por la actriz Regina Torné.
} 
ro de producciones de corte similar, entre ellas su secuela Las ficheras: Bellas de noche II, dirigida también por Delgado en 1977, ${ }^{20}$ que se caracterizaron por la exhibición de desnudos, por el uso del albur (o humoradas con doble sentido) y del habla coloquial (con "palabrotas" incluidas) como recursos de comicidad. Asimismo, al traer a escena aspectos vinculados con la sexualidad, estos films no solamente abordaron la figura de la fichera o trabajadora del cabaret, sino que, tal como destaca Ramírez Berg (1992), emplearon también en las tramas tópicos que notamos ausentes en las películas de cabareteras que les precedieron, como la figura del homosexual, el cual es ridiculizado desde el estereotipo del "amaneramiento", pero al mismo tiempo asimilado especularmente con la figura del hombre viril o "macho", situación que el autor interpreta como la revelación "del estado de desesperación del patriarcado en crisis" (p. 125).

La emergencia de estas películas coincidió con un fenómeno internacional conocido como la época del destape, correspondiente con el descenso de las restricciones de la censura, y que permitió la representación de situaciones dramáticas asociadas a una sexualidad más explícita, así como desnudos (principalmente femeninos) y bailes sensuales, que también proliferaron en los medios gráficos y televisivos. La emergencia de estos tópicos en un nivel más manifiesto fue coincidente con lo que sucedía en otros países, como lo demuestra el análisis de Pablo Piedras y Sophie Dufays (2019), en el cual no solo rescatan el film iniciador del género de ficheras sino también un título venezolano simultáneo llamado El pez que fuma (1977), de Román Chaulbaud, y en donde resaltan su combinación con el aprovechamiento de los usos de la canción popular $^{21}$. Si bien el cine de ficheras fue novedoso en la pantalla mexicana, esto implicó, sin embargo, una suerte de continuidad de una tradición cinematográfica en el país, que tuvo en cuenta espacios como el cabaret y tópicos como el ejercicio de la prostitución aun desde tiempos tan tempranos como principios de los años

20 Otros films fueron Noches de cabaret (1978), Muñecas de medianoche (1979) y Las tentadoras (1980), los tres de Rafael Portillo, y de forma más tardía y asociados con las sexycomedias, Los plomeros y las ficheras (1987) y El rey de las ficheras (Los plomeros II) (1989), ambos de Víctor Manuel Castro.

${ }^{21}$ En Argentina, el destape provocó un gran número de films, muchos interpretados por la dupla cómica compuesta por Jorge Porcel y Alberto Olmedo, con los explícitos títulos de Los hombres solo piensan en eso (1976), de Enrique Cahen Salaberry, Fotógrafo de señoras (1978), de Hugo Moser, Encuentros muy cercanos con señoras de cualquier tipo (1978), de Hugo Moser, A los cirujanos se les va la mano (1980), de Hugo Sofovich y Los reyes del sablazo (1984), de Enrique Carreras. En otro orden también pueden mencionarse las películas interpretadas por Isabel Sarli, que explotan la exhibición de su voluminoso cuerpo. En Brasil también hubo una corriente de films que aluden explícitamente a la sexualidad, como las célebres pornochanchadas de los años setenta, entre las cuales destacan A viúva virgen (1972), de Pedro Carlos Rovai, Ainda agarro esta vizinha (1974), de Pedro Carlos Rovai, Histórias que nossas babas não contavam (1979), de Oswaldo de Oliveira y A noite das taras (1980), de Ody Fraga, aunque unas de las más trascendentes películas brasileñas con contenido erótico ha sido Doña Flor y sus dos maridos (1976) (traducida como Dona Flor e seus dois maridos), de Bruno Barreto. Finalmente, España también ha tenido una cinematografía del destape apenas se debilitaron las restricciones impuestas por la dictadura franquista, con películas como El amor del capitán Brando (1974), de Jaime de Armiñán, La trastienda (1976), de Jorge Grau, Los placeres ocultos (1977), de Eloy de la Iglesia y La muchacha de las bragas de oro (1980), de Vicente Aranda, derivando en el cineasta Pedro Almodóvar como uno de los principales creadores de tinte autoral. Como podemos notar, la impronta que los Calderón promovieron en sus films de temática erótica no fue un caso aislado en Hispanoamérica. 
treinta, con films ya clásicos como Santa (1931), de Antonio Moreno, y La mujer del puerto (1933), de Arcady Boytler, pasando también por el célebre cine de rumberas, en donde dicho espacio y personajes aflorarían en una extraña mixtura de ritmos candentes y tramas melodramáticas.

No obstante, las ficheras trajeron un nuevo modelo de seducción, ya no basado en la sugestión de las rumberas o en la sofisticación o carácter enérgico de grandes divas como Dolores del Río y María Félix, sino en un modelo de exhibicionismo que venía perfilándose poco a poco desde la década del cincuenta. El personaje de la rumbera dio lugar a la fichera, pero no por ello la despojó de algunas características comunes. La rumbera, de pasado trágico y con un alto determinismo, es una figura dotada de cualidades para el baile, atrayendo tanto a sus clientes en el cabaret como al espectador, que se deleita en sus contorneos cuando hace una pausa a sus desgracias y se enfoca en la generación del espectáculo. La fichera también es presentada como víctima de circunstancias difíciles, aunque carente de aquel sino trágico adjudicado a la rumbera, pues el cine de ficheras se abocó al desarrollo de tramas cómicas. Aunque tanto la una como la otra se ganan la vida bailando con los clientes, la fichera, como evidencia del destape antes mencionado, muestra su cuerpo de forma más desinhibida (léase, sin ropa) y no oculta bajo ningún eufemismo el ejercicio de la prostitución.

La distancia temporal entre ambos tipos de films no implicó que el cambio entre un personaje y otro se haya dado de manera súbita, pues con títulos como La virtud desnuda (1957), de José Díaz Morale, y La diana cazadora (1957), de Tito Daviso, los Calderón marcaron una transición en la representación de las figuras femeninas. Aunque estas dos películas muestran personajes asentados en el antiguo prototipo de la mujer fatal que busca destruir a los hombres, la novedad que instalaron fue la presentación de desnudos femeninos, utilizados como instrumentos de promoción, abriendo paso al empleo de estas estrategias para atraer a los públicos. Para la época en que surgió el cine de ficheras, y su derivado, las sexycomedias ${ }^{22}$, la exposición de cuerpos desnudos en las salas comerciales ya era moneda corriente. En definitiva, fue un subgénero con políticas de mercado que alentaban la aglomeración de públicos por medio de esta clase de efectismos, a los que se sumaba la elaboración de tramas escapistas y sin exigencias para su seguimiento, así como el empleo de recursos mínimos para la producción. Las ficheras lograron concentrar a los públicos urbanos, que se sentían identificados con los personajes que allí circulaban, y generaron cuantiosas ganancias para la industria, aunque en detrimento de la cualidad estética y favoreciendo el desprestigio de los sectores intelectuales del cine.

22 Algunas de las principales sexycomedias que produjeron los Calderón fueron La pulquería (1981), de Víctor Manuel Castro, Macho que ladra no muerde (1984), de Víctor Manuel Castro y Damián Acosta Esparza y Huele a gas (1986), de Víctor Manuel Castro. 
Ya por fuera de las actividades cinematográficas de los Calderón, las comedias eróticas permanecerían en la subsiguiente década, los años noventa, con comedias sexuales románticas, según la denominación de Deborah Shaw (2006 p. 55)23, que tuvieron éxito entre las clases medias tras la proliferación de multisalas en los sectores urbanos de México. La cabaretera seguiría trascendiendo en la cultura mexicana todavía en tiempos contemporáneos, con la figura de Astrid Hadad, analizada por De Bragança (2007) como continuadora de una tradición que sigue la línea de las famosas rumberas, pero con el fin de resaltar los procesos de subalternización impuestos por dicha tradición en pos de un discurso multicultural. Finalmente, también en el presente ha sido resemantizada la figura de la fichera a través de la realización del documental Bellas de noche (2016), de María José Cuevas, en donde esta es reivindicada como parte de la historia cultural del país y reactualizada en el espacio cotidiano, asimilando su retirada de los escenarios con el efecto del paso de los años en las vedettes ${ }^{24}$.

\section{Conclusiones}

Las nuevas experiencias, que reemplazaron los patrones que la época clásica había logrado estandarizar, produjeron nuevos paradigmas, como la presencia de nuevos tipos de estrellas. Ya no estaban los grandes nombres de la llamada Edad de Oro como Jorge Negrete o Pedro Infante, pero emergieron Jorge Rivero y Armando Silvestre, actualizaciones de la figura del galán, o Rafael Inclán, Lalo "El Mimo" y Alfonso Zayas, que instalaron un tipo de masculinidad opuesta a la de los galanes, basada en su comicidad y en una mayor identificación con el público. Igual en el caso de las actrices: no contábamos con los contorneos alegres de las rumberas cubanas, pero emergerían Ana Luisa Peluffo, Sasha Montenegro, Columba Domínguez, Angélica Chain y Lyn May, estimulando el voyeurismo masculino con un prototipo de mujer en exhibición, y despojado de la mitificación de las antiguas estrellas del cine mexicano. Estas figuras más "carnales" evidencian un deseo de instalación de una cotidianeidad equiparable a la realidad de los espectadores, pues las tramas estaban orientadas hacia el habla coloquial, y mostraron individuos con debilidades como las de cualquier mortal.

El cine de ficheras y sexycomedias fue una especie de contrapartida del cine de luchadores, pues allí encontramos héroes fornidos, valientes y dispuestos a combatir el mal, insertos en un ambiente de enfrentamiento con fuerzas ya no tan cotidianas.

${ }^{23}$ La autora analiza específicamente dos películas de los años noventa, Sólo [sic] con tu pareja (1991), de Alfonso Cuarón y Sexo, pudor y lágrimas (1998), de Antonio Serrano Argüelles, a través de las cuales dilucida la existencia de una mixtura entre alta y baja cultura enfocada en los nuevos públicos populares.

24 Para un análisis detallado sobre este film y otros títulos representativos de esta memoria cultural referenciada, ver Flores (2020b). Asimismo, para complementar este artículo recomendamos el visionado de la mencionada película Perdida (2014), de sensacine que no solo hace mención del legado del cine de ficheras sino de toda la trayectoria cinematográfica de la familia Calderón. 
También pueden equipararse sus figuras con el halo mítico dado antes a las heroínas melodramáticas del cabaret. Así lo establece Aviña (2004) al afirmar que el cine de luchadores sustituyó a las películas de rumberas: "[l]os vestidos de brillante satén se reducían a llamativas máscaras; las secreciones habituales eran cambiadas por el sudor y la sangre, y los colchones desvencijados de los hoteles de paso se trocaban en la lona de un cuadrilátero" (p. 189). Los nuevos tiempos requerían una actualización de los productos audiovisuales de éxito, ofreciendo a los espectadores dos variantes para su elección. De un lado del ring, el cine fantástico y de terror con sus luchadores sumidos en aventuras sobresalientes e inexplicables, y del otro, los espectadores podían avivar la vertiente más costumbrista y afincada en enredos, que fueron las comedias con contenido erótico.

Si partimos de los interrogantes planteados en la introducción de este artículo, hemos podido divisar que los productores Calderón buscaron solventar las problemáticas de continuidad de una industria en crisis, confrontada por la emergencia de nuevos paradigmas estéticos propios del cine moderno, con la elaboración de un corpus de films asentado en las tres alternativas genéricas aquí analizadas. Estas partieron de los gustos populares, de la organización de tramas simples y previsibles tendientes a la conformidad de espectadores que aspiraban al esparcimiento, y de las ventajas comerciales provistas, ya sea por cierta liberación de la censura o por la pregnancia en los medios de los personajes populares que estas películas promocionaban.

Teniendo en cuenta los nuevos géneros que empezaron a emprenderse dentro del esquema industrial de corte popular que representaron los Calderón, nos preguntarnos entonces acerca de la funcionalidad que estos tuvieron para el sostenimiento de aquella industria. Como señalamos, México ha vivido en estas décadas transformaciones que abarcan tanto aspectos operativos como narrativos y estéticos, partiendo de los cambios en la cinematografía mundial, que incluyeron también una coyuntura histórica volcada a reformas sociales. Los años sesenta y setenta no tuvieron la afluencia de públicos nacionales y foráneos que había tenido el cine del país en su Edad de Oro. Sin embargo, provocaron la emergencia de nuevos directores con preocupaciones alineadas al llamado Nuevo Cine Latinoamericano, que consolidó abordajes alejados del clasicismo, pero con poca receptividad del gran público. Aun así, México mantuvo una línea afianzada en una perspectiva industrialista, teniendo a Guillermo Calderón como un prototipo de la búsqueda de nuevos formatos populares, que vinieron a proponer una continuidad de las viejas estructuras, como una pretensión de renacimiento de aquella industria que ya no estaba tan vigente como en las décadas precedentes. La proliferación de films de terror, luchadores y ficheras trajo supervivencia a este productor que puso sobre la mira los gustos del gran público, para expandir sus posibilidades comerciales, desatando así la confrontación entre dos paradigmas de abordaje del cine. 
Con base a esto, la industria se actualizó por medio de la instalación de géneros clásicos pero encarados desde propuestas que respondían a los nuevos tiempos. Con el cine fantástico y de terror y las películas de luchadores, observamos un fenómeno en particular en torno a la hibridación: mientras algunos representantes del primero incluyeron a los nuevos personajes de la cultura popular mexicana, los luchadores, las películas del segundo subgénero también buscaron introducir a los héroes y villanos del ring en ambientes de fantasía y horror. Se dio aquí lo que otrora analizaran Ruétalo y Tierney (2009) acerca de lo que se ha conocido como latsploitation cinema, y asimismo Syder y Tierney (2005) sobre el mexploitaition cinema, en tanto ciertas características del cine de terror que hemos podido notar en los análisis, se han mixturado con una producción de bajo presupuesto que introduce mitos nacionales junto a referencias de la lucha libre, de gran pregnancia en el público mexicano, a tal punto que se han convertido en films de culto aun en el tiempo presente. Por su parte, el cine de ficheras fue una continuidad de las películas de rumberas, pues ambos incluyeron al mismo personaje, la mujer que baila, que ofrece un espectáculo artístico o que se involucra sentimental y trágicamente con los clientes. Pero las ficheras estarían despojadas de aquel fatalismo presente en las rumberas, añadiéndoles un ingrediente inexistente en los anteriores films, que es la comicidad, aunque no por eso carentes de alguna historia triste que contar. La saturación de los tópicos derivó en la salida del espacio del cabaret con la producción de las sexycomedias, que instalaron aquellas tramas amatorias en ámbitos aún más cotidianos, resultando en el último intento de Calderón por su permanencia en la industria. A partir de los noventa dejaría de producir dejando su propio legado de un cine de pocas pretensiones artísticas y asentado en el entretenimiento ligero de los espectadores, constituyéndose esto en un objeto de estudio aún incipiente por la permanencia de cierto menoscabo en torno a los cines populares, pero que abre puertas a nuevos estudios sobre los géneros clásicos, y su continuidad y capacidad de reactualización con el correr de los años.

\section{Referencias}

Alazraki, B. (dir.) (1961). Muñecos infernales [película]. Calderón Producciones.

Alazraki, B. (dir.) (1962). Espiritismo [película]. Calderón Producciones.

Asociación de Documentalistas de México. (2007). Discurso pronunciado por el presidente Echeverría en la ceremonia de entrega de Arieles 1972. El cine independiente, ¿̇hacia dónde? Editorial La Rana del Sur.

Aviña, R. (2004). El cine de luchadores. En Una mirada insólita. Temas y géneros del cine mexicano. Editorial Océano de México.

Boytler, A., y Sevilla, R. (dir) (1934). La mujer del Puerto. [película]. FilmAffinity

Browning, T. (dir.) (1936). Muñecos infernales. [película]. Productora Metro-Goldwyn-Mayer 
Cahen, E. (dir) (1976). Los Hombres Piensan Sólo en eso. [película]. IMDb

Carreras, E. (dir) (1983). Los reyes del sablazo. [película]. IMDb

Carta de Guillermo Calderón S. a Guillermo Carter, fechada el 7 de septiembre de 1961 (Archivo Permanencia Voluntaria).

Calderón, G. (1965, 4 de marzo). [Carta a Antonio Expédito Fernández]. Actas del Congreso Internacional. Archivo Permanencia Voluntaria.

Carroll, N. (2005). Filosofía del terror o paradojas del corazón. Antonio Machado Libros.

Castro, V. (dir.) (1981). La Pulquería. Ipelícula]. FilmAffinity

Castro Ricalde, M. y Mckee Irwin, R. (2011). El cine mexicano "se impone". Mercados internacionales y penetración cultural en la época dorada. Universidad Nacional Autónoma de México; Filmoteca de la UNAM.

Chalbaud, R. (dir) (1977). El Pez que Fuma. [película]. Filmaffinity

Cuarón, A. (dir.). (1991). Sólo con tu pareja. [película]. Sensacine México

Cuevas, M.J. (dir.)(2016). Bellas de Noche. [documental]. Filmaffinity

Coria, J.F. (2018, 21 de marzo). "La comedia neo-con". Icónica Pensamiento fílmico. http:// revistaiconica.com/comedia-cine-mexicano/

Costa, P. (1988). La "apertura" cinematográfica. México 1970-1976. Universidad Autónoma de Puebla.

Davison, T. (dir) (1957). La Diana Cazadora. [película].IMDb

Díaz, J. (dir) (1957). La virtud desnuda. Ipelícula]. IMDb

De Bragança, M. (2007). Performance, política e multiculturalismo no cabaré popular de Astrid Hadad. Revista de Letras, 47(2), 99-120.

De Fuentes, F. (dir.) (1934). El fantasma del convento [película]. FilmAffinity

Fernández, A. (2007). Crimen y suspenso en el cine mexicano. 1946-1955. El Colegio de Michoacán.

Flores, S. (2018a). El cine mexicano más allá de las fronteras: aproximación a las actividades de José U. Calderón. Revista Europeia de Estudos Artísticos, 9 (2), 20-36.

Flores, S. (2018b). Entre monstruos, leyendas ancestrales y luchadores populares: la inserción del Santo en el cine fantástico mexicano. Secuencias, (48), 9-33.

Flores, S. (2020a). Las actividades cinematográficas de José y Rafael Calderón: un caso de omisión en la historia del cine regional y transnacional en México. Arte, Individuo y Sociedad, 32(3), 581-602.

Flores, S. (2020b). Otros modos de escribir la historia del cine: la cinematografía mexicana según tres documentales de los últimos años. Fotocinema, (20), 165-196.

Frías, I. L. (2013). El nuevo cine latinoamericano de los años sesenta. Entre el mito político y la modernidad fílmica. Universidad de Lima; Fondo Editorial. 
García, M (2017). ¿̇Imaginar el futuro? 2033 y el resurgimiento del cine mexicano de ciencia ficción. Revista Iberoamericana, 83(259-260), 629-643.

García Riera, E. (1993). Historia documental del cine mexicano. 7. 1953-1954. Universidad de Guadalajara; Gobierno de Jalisco; Consejo Nacional para la Cultura y las Artes; Instituto Mexicano de Cinematografía.

Gunckel, C. (2015). Mexico on Main Street. Transnational Film Culture in Los Angeles before World War II. Rutgers University Press.

Lie, Nadia (2016). Lo transnacional en el cine hispánico: deslindes de un concepto. Foro hispánico: revista hispánica de Flandes y Holanda, (51), 17-35.

Martínez, J., Padilla, R., Schatán, C., y Vega, V. (2010). La industria cinematográfica en México y su participación en la cadena global de valor. Cepal.

Meyer, E (1976) (coord.). René Cardona. Cuadernos de la Cineteca Nacional. Testimonios para la historia del cine mexicano 2. Cineteca Nacional.

Moser, H. (dir) (1978). Fotógrafo de Señoras. Ipelícula]. IMDd.

Moser, H. (dir) (1978). Encuentros muy cercanos con señoras de cualquier tipo. [película]. IMDd

Moreno, A. (dir) (1932). Santa. [película]. FilmAffinity

Novell, N. (2008). Literatura y cine de ciencia-ficción. Perspectivas teóricas [tesis de doctorado, Universidad Autónoma de Barcelona). https://www.tdx.cat/bitstream/handle/10803/4892/nnmldel.pdf

Paranaguá, P. A. (2003). Tradición y modernidad en el cine de América Latina. Fondo de Cultura Económica.

Peón, R. (dir.) (1933). La llorona [película]. Filmaffinity

Peredo Castro, F. (2011). Cine y propaganda para Latinoamérica. México y Estados Unidos en la encrucijada de los años cuarenta. Universidad Nacional Autónoma de México.

Piedras, P. y Dufays, S. (2019). Canción popular, melodrama y cabaret en Bellas de noche y El pez que fuma. Chasqui, 48(2), 53-70.

Portillo, R. (dir.) (1957). La momia Azteca. [Película]. Calderón Productora .

Ramírez, C. (1992). Cinema of solitude. A critical study of Mexican film, 1967-1983. University of Texas Press.

Rivero, F. (dir.) (1943). La posada sangrienta [película]. Filmaffinity

Roas, D. (2018). Behind the Frontiers of the Real: a Definition of the Fantastic. Palgrave Pivot.

Rosas, A. (2000). Auge, ocaso y renacimiento de la exhibición de cine en la ciudad de México (1930-2000). Alteridades, 10(20), 107-116.

Rosas, A. (2017). Ir al cine: antropología de los públicos, la ciudad y las pantallas. Editorial Gedisa.

Ruétalo, V. y Tierney, D. (2009). Latsploitation exploitation cinemas and Latin America. Routledge.

Saavedra, I. (2006). El fin de la industria cinematográfica mexicana, 1989-1994. Estudios Interdisciplinarios De América Latina Y El Caribe, 17(2), 107-127. 
Shaw, D. (2006). The Mexican romantic sex comedy. The emergence of a middlebrow filmmaking in the 1990s. Middlebrow cinema. Routledge.

Shaw, D. y De la Garza, A. (2010). Introducing transnational cinemas. Transnational cinemas, 1(1), 3-6.

Serrano, A. (dir.). (1999). Sexo, sudor y lagrimas. [pelicula]. Sensacine.com

Sofovich, H. (dir) (1980). A los Cirujanos se les Van las Manos. [película].IMDb

Syder, A. y Tierney, D. (2005). Importation/Mexploitation, or, How a Crime-Fighting, Vampire Slaying-Mexican Wrestler Almost Found Himself in an Italian Sword-and-Sandal Epic. Horror International. Wayne State University Press.

Todorov, T. (1981). Definición de lo fantástico. Introducción a la literatura fantástica. Premia editora de libros.

Wood, R. (1985). An Introduction to the American Horror Film. Movies and methods: an anthology, 2, 195-220. 